\title{
AIR-ICE-OCEAN FEEDBACK MECHANISMS AND ICE OSCILLATION ON MILLENNIAL TIME SCALES
}

\author{
by
}

P.C. Chu

(Department of Oceanography, Naval Postgraduate School, Monterey, CA 93943, U.S.A.)

\section{ABSTRACT}

Air-ice-ocean feedback mechanisms, which are not conventionally incorporated within either climate or glacial models, are investigated to illustrate their potential role in generating ice advance/retreat on the time scale of $10^{3}-10^{4}$ years; i.e. for examining the internal causes for the ice oscillation.

Three main feedback loops are found from a coupled air-ice-ocean model developed in this paper: (a) ice advance $\rightarrow$ lower air temperature $\rightarrow$ ice freezing $\rightarrow$ ice advance; and (b) ice advance $\rightarrow$ higher ocean temperature $\rightarrow$ ice melting $\rightarrow$ ice retreat; (c) ice advance/retreat $\rightarrow$ modification of evaporation rate $\rightarrow$ change of ice accumulation rate and sea-level height $\rightarrow$ ice advance/retreat. The relative strength of the three feedback mechanisms determines the characteristics of the modes: growing or decaying, oscillatory or nonoscillatory. The solutions show the generation of growing oscillatory modes with the time scale of $10^{3}-10^{4}$ years in certain parameter ranges.

\section{INTRODUCTION}

In trying to understand ice oscillation and related climatic change, one may first ask: is ice advance/retreat caused by external or internal forcings? The external forcings are agencies outside the Earth system, such as astronomically caused changes in the Earth's orbital parameters.

Internal forcings, on the other hand, are processes and mechanisms present within the Earth system, giving rise to self-excited glacial fluctuations. The temperature-albedo feedback mechanism associated with long and short wave radiation fluxes at the Earth's surface are given considerable attention in glacial and climate models (Källénand others, 1979; Oerlemans and van der Veen, 1984). However, the role of the hydrological cycle on the ice advance/retreat is given less attention although it is realized that ice freeze/melt and evaporation/precipitation are contributors to the change of air and ocean temperatures, which in turn influence the ice. The purpose of this paper is to investigate, in its simplest form, a possible feedback mechanism in the air-ice-ocean system regarding the hydrological cycle. The ice advance/ retreat on the continent is not included in this work.

Figure 1 shows the main physical processes in the coupled system. From the global point of view, ice advance isolates the ocean from the atmosphere and reduces the heat loss from the ocean surface, which in turn decreases the air temperature and increases the ocean temperature. The air and ocean feed back into the ice through two different mechanisms (Fig. 2): (1) thermodynamical feedback; the increase of ocean temperature melts the ice and causes ice retreat (negative feedback between ice and ocean), however, the decrease of air temperature causes freezing and makes the ice further advance (positive feedback between ice and air): (2) mechanical feedback; the modification of the atmospheric and oceanic temperatures varies the surface evaporation rate, which in turn changes the sea-level height and the ice accumulation rate. Both effects lead to a further change of the ice flow.

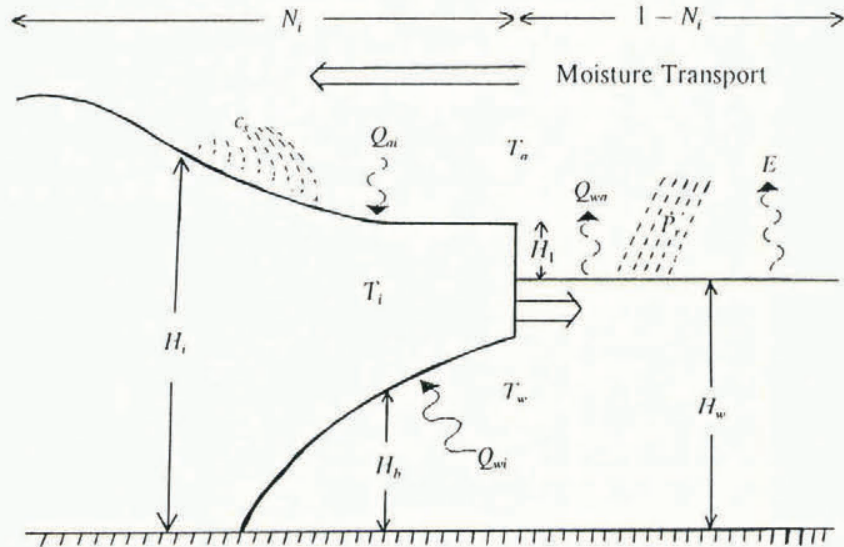

Fig. 1. Physical processes in the coupled air-ice-ocean system.

\section{MODEL DESCRIPTION}

\section{Ice advance/retreat}

The total surface, ice covered, and open ocean areas are set to be $1, N_{\mathrm{i}}$, and $1-N_{\mathrm{i}}$, respectively (Fig. 1). The ice is assumed to be isotropic with thickness $H_{\mathrm{i}}$. Following Weertman (1957), the ice-spreading rate is computed by:

$$
\left\langle\dot{\varepsilon}_{\mathrm{h}}\right\rangle=A\left(\frac{1}{4} \rho_{\mathrm{i}} g H_{1}\right)^{n}
$$

where $\rho_{\mathrm{i}}$ is the ice density. $H_{1}$ is the height between the ice top and the sea-level (Fig. 1). Values of $n$ vary from about 1.5 to 4.2 with a mean of about 3 , and for randomly oriented polycrystalline ice at $-10^{\circ} \mathrm{C}$ and $n=3$, a value $A=3 \times 10^{-8} \mathrm{a}^{-1} \mathrm{kPa}^{-3}$ is reasonable for ice stress (Weertman, 1973). The angle brackets denote values averaged over ice thickness. The time rate of change of ice coverage $N_{\mathrm{i}}$ contains mechanical and thermodynamical (ice edge freezing/melting) parts:

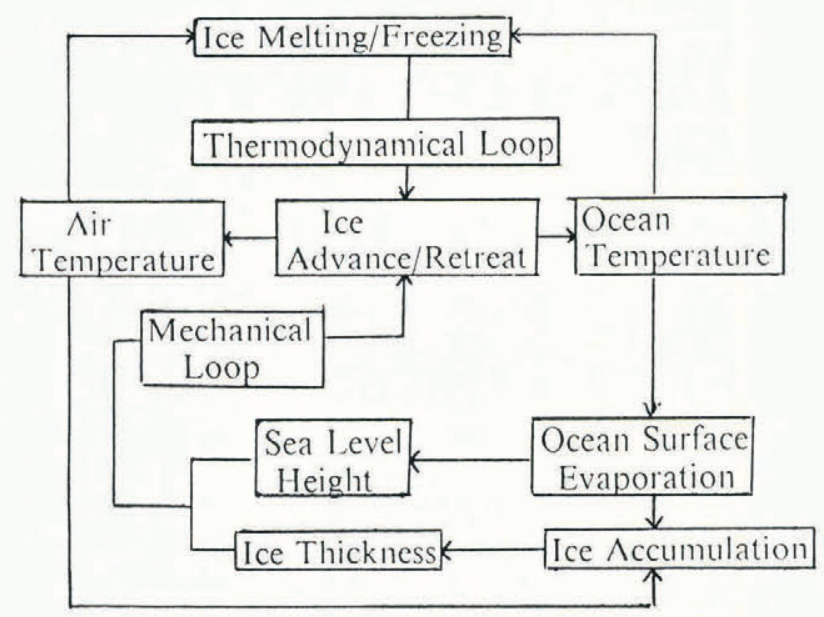

Fig. 2. Feedback mechanisms among air, ice, and ocean. 


$$
\frac{\partial N_{\mathrm{i}}}{\partial t}=N_{\mathrm{i}}\left\langle\dot{\varepsilon}_{\mathrm{h}}\right\rangle+\frac{\left(1-N_{\mathrm{i}}\right) F}{H_{\mathrm{i}}}
$$

where $H_{\mathrm{i}}$ is the ice thickness, and $F$ is the freezing rate at the ice edge. Following Killworth (1979), the heat flux is accomplished through an exchange coefficient $K$ and is of the form $K\left(T-T_{\mathrm{f}}\right)$, where $T_{\mathrm{f}}$ represents the freezing point of sea water. Therefore the freezing rate is computed by:

$$
F=-\frac{1}{\rho_{\mathrm{i}} L_{\mathrm{i}}}\left[\rho_{\mathrm{w}} c_{\mathrm{pw}} K_{\mathrm{wi}}\left(T_{\mathrm{w}}-T_{\mathrm{f}}\right)+\rho_{\mathrm{a}} c_{\mathrm{pa}} K_{\mathrm{ai}}\left(T_{\mathrm{a}}-T_{\mathrm{f}}\right)\right]
$$

where $K_{\text {wi }}, K_{\text {ai }}$ are the heat exchange coefficients for water-ice and air-ice, respectively. $L_{\mathrm{i}}$ is the latent heat of ice. If $T_{\mathrm{w}}, T_{\mathrm{a}}$ are greater than $T_{\mathrm{f}}, F$ is taken as a negative value, which means ice melting.

\section{Time rate of change of ice thickness}

Based on the equation of continuity, Shumskiy (1965) proposed a method of determining ice-thickness changes by comparing the accumulation rate with horizontal strain-rates. The time rate of change of ice thickness becomes:

$$
\frac{\partial H_{\mathrm{i}}}{\partial t}=c_{\mathrm{s}}-H_{\mathrm{i}}\left\langle\dot{\varepsilon}_{\mathrm{h}}\right\rangle-V_{\mathrm{i}} \cdot \nabla H_{\mathrm{i}}
$$

where $c_{\mathrm{s}}$ is ice accumulation rate, and $V_{\mathrm{i}}$ is vertical mean ice velocity, which links to ice thickness and bedrock topography. It is commonly believed that the non-linear inertial term $-V_{\mathrm{i}} \cdot \nabla H_{\mathrm{i}}$ in ice-sheet models relates to the long time scale of glacial cycles; however, for simplicity this term is neglected from the present model, i.e.:

$$
\frac{\partial H_{\mathrm{i}}}{\partial t}=c_{\mathrm{s}}-H_{\mathrm{i}}\left\langle\dot{\varepsilon}_{\mathrm{h}}\right\rangle
$$

which means that the current coupled system excludes the variations with long time scales comparable to the glacial cycles.

\section{Time rate of change of ocean depth}

From a thermodynamical point of view, the surface evaporation and ice freezing/melting are two major processes to change the ocean elevation, i.e.:

$$
\frac{\partial H_{\mathrm{w}}}{\partial t}=-E-\frac{\left(1-N_{\mathrm{i}}\right) \rho_{\mathrm{i}} F}{\rho_{\mathrm{w}}}
$$

where $H_{\mathrm{w}}$ is the depth of the ocean, $\rho_{\mathrm{w}}$ is the sea-water density, and $E$ is the surface evaporation rate computed by the bulk formula:

$$
E=\left(1-N_{\mathrm{i}}\right) C_{\mathrm{D}}\left|V_{\mathrm{a}}\right| \frac{\rho_{\mathrm{a}}}{\rho_{\mathrm{w}}}\left[q_{\mathrm{s}}\left(T_{\mathrm{w}}\right)-q_{\mathrm{a}}\right]
$$

where $C_{\mathrm{D}}$ is the drag coefficient, $V_{\mathrm{a}}$ is the surface wind, $q_{\mathrm{S}}$ is the saturated mixing ratio, and $q_{\mathrm{a}}$ is mixing ratio near the ocean surface.

\section{Heat equations for air and ocean}

The heat equations for the atmosphere and ocean are:

$$
\begin{aligned}
& \frac{\partial T_{\mathrm{a}}}{\partial t}=\frac{1}{\rho_{\mathrm{a}} c_{\mathrm{pa}} H_{\mathrm{a}}}\left[-N_{\mathrm{i}} Q_{\mathrm{ai}}+\left(1-N_{\mathrm{i}}\right) Q_{\mathrm{wa}}\right] \\
& \frac{\partial T_{\mathrm{w}}}{\partial t}=-\frac{1}{\rho_{\mathrm{w}} c_{\mathrm{pw}} H_{\mathrm{w}}}\left[N_{\mathrm{i}} Q_{\mathrm{wi}}+\left(1-N_{\mathrm{i}}\right) Q_{\mathrm{wa}}\right]
\end{aligned}
$$

where $T_{\mathrm{a}}, T_{\mathrm{w}}$ are temperatures of air and ocean. $H_{\mathrm{a}}$ is the depth of the atmosphere. $Q_{\mathrm{ai}}, Q_{\mathrm{wi}}$ are, respectively, the heat fluxes from air and ocean to ice and $Q_{\mathrm{wa}}$ is the heat flux from ocean to atmosphere. Equations (2), (4), (5), (6), and (7) are the basic equations of our model.

\section{MEAN STATE AND PERTURBATIONS}

\section{Parameterization of perturbations}

Mean state of the coupled system $\left(N_{\mathrm{i}}, H_{\mathrm{i}}, H_{\mathrm{w}}, T_{\mathrm{a}}\right.$, $\left.T_{\mathrm{w}}, E\right)$ is obtained by the zero time rate of change in the basic Equations (2), (4), (5), (6) and (7). When the coupled system is perturbed from its mean state, the feedback mechanisms make the perturbation either grow or dampen. Assume that the perturbation of the ocean-surface evaporation rate is caused by the fluctuations of sea-surface temperature $\left(T^{\prime}{ }_{\mathrm{w}}\right)$, surface wind speed $\left(V^{\prime}{ }_{\mathrm{a}}\right)$, and the ice coverage $\left(N^{\prime}{ }_{\mathrm{i}}\right)$, i.e.:

$$
E^{\prime}=\left(1-N_{\mathrm{i}}\right) C_{\mathrm{D}}\left|V_{\mathrm{a}}\right| \frac{\rho_{\mathrm{a}} \mathrm{d} q_{\mathrm{s}}\left(T_{\mathrm{w}}\right)}{\rho_{\mathrm{w}}} T_{\mathrm{w}}^{\prime}+
$$

$$
+\frac{E}{\left|V_{\mathrm{a}}\right|} V_{\mathrm{a}}^{\prime}-\frac{E}{\left(1-N_{\mathrm{i}}\right)} N_{\mathrm{i}}^{\prime} \text {. }
$$

Ice advance results in an increase of the ocean temperature and a decrease of the surface air temperature. The greater ice coverage will partly insulate the atmosphere from the ocean, decreasing the evaporation (see term (3)); but in locations where the ocean and atmosphere are in direct contact, the warmer ocean temperatures will increase the ocean evaporation rate, which is called the local SST-evaporation coupling (see term (1)). Also the colder air temperatures will strengthen the thermally driven surface wind (due to the larger surface air temperature gradient) and consequently increase the evaporation rate, which is called the wind-evaporation coupling (see term (2)). The net effect as to whether the ice advance increases or decreases the evaporation rate is thus uncertain. According to Chu's (1989) thermally driven surface-wind formula, the term (2) in Equation (8a) is an order of magnitude smaller than the term (1), and therefore is neglected from the equation, leading to:

$$
E^{\prime}=\left(1-N_{\mathrm{i}}\right) \gamma \frac{\rho_{\mathrm{a}}}{\rho_{\mathrm{w}}} \frac{\mathrm{d} q_{\mathrm{S}}\left(T_{\mathrm{w}}\right)}{\mathrm{d} T} T_{\mathrm{w}}^{\prime}-\frac{E}{\left(1-N_{\mathrm{t}}\right)} N_{\mathrm{i}}^{\prime}
$$

where $\gamma\left(=C_{\mathrm{D}}\left|V_{\mathrm{a}}\right|\right)$ is the moisture exchange coefficient.

The relationships among the surface evaporation rate $E^{\prime}$, the precipitation rate on the ocean $P_{\mathrm{r}}^{\prime}$, and the ice accumulation rate $c_{\mathrm{S}}^{\prime}$ are simplified as:

$$
P_{\mathrm{r}}^{\prime}=\left(1-N_{\mathrm{i}}\right) E^{\prime}, c_{\mathrm{S}}^{\prime}=N_{\mathrm{i}} E^{\prime}
$$

which means the surface evaporation is the source for precipitation and ice accumulation. Following Killworth (1979), the heat fluxes are computed by:

$$
\begin{aligned}
& \frac{Q_{\mathrm{ai}}^{\prime}}{\rho_{\mathrm{a}} c_{\mathrm{pa}}}=K_{\mathrm{ai}}\left(T_{\mathrm{a}}^{\prime}-T_{\mathrm{i}}^{\prime}\right), \\
& \frac{Q_{\mathrm{wa}}^{\prime}}{\rho_{\mathrm{a}} c_{\mathrm{pa}}}=K_{\mathrm{wa}}\left(T_{\mathrm{w}}^{\prime}-T_{\mathrm{a}}^{\prime}\right), \\
& \frac{Q_{\mathrm{wi}}^{\prime}}{\rho_{\mathrm{w}} c_{\mathrm{pw}}}=K_{\mathrm{wi}}\left(T_{\mathrm{w}}^{\prime}-T_{\mathrm{i}}^{\prime}\right)
\end{aligned}
$$

where $c_{\mathrm{pa}}, c_{\mathrm{pw}}$ are the specific heats for air and ocean, respectively, and $K_{\mathrm{ai}}, K_{\mathrm{wa}}$, and $K_{\mathrm{wi}}$ are heat-exchange coefficients between the corresponding two components. by:

The perturbation of lateral freezing rate is computed

$$
F^{\prime}=-\frac{\left(\rho_{\mathrm{w}} c_{\mathrm{pw}} K_{\mathrm{wi}} T_{\mathrm{w}}^{\prime}+\rho_{\mathrm{a}} c_{\mathrm{pa}} K_{\mathrm{ai}} T_{\mathrm{a}}^{\prime}\right)}{\rho_{\mathrm{i}} L_{\mathrm{i}}}
$$

where $L_{\mathrm{i}}$ is the latent heat of the ice. 
Timescales of perturbations

Four main timescales appear in this coupled system. They are:

$$
\tau_{\mathrm{a}} \equiv\left[\frac{K_{\mathrm{ai}}}{H_{\mathrm{a}}} N_{\mathrm{i}}+\frac{K_{\mathrm{wa}}}{H_{\mathrm{a}}}\left(1-N_{\mathrm{i}}\right)\right]^{-1}
$$

which is the atmospheric relaxation timescale:

$$
\tau_{\mathrm{w}} \equiv\left[\frac{K_{\mathrm{wi}}}{H_{\mathrm{w}}} N_{\mathrm{i}}+\frac{\rho_{\mathrm{a}} c_{\mathrm{pa}} K_{\mathrm{wa}}}{\rho_{\mathrm{w}} c_{\mathrm{pw}} H_{\mathrm{w}}}\left(1-N_{\mathrm{i}}\right)\right]^{-1}
$$

which is the oceanic relaxation timescale,

$$
\tau_{\mathrm{e}} \equiv \frac{Q_{\mathrm{wa}}}{\left(Q_{\mathrm{wa}}-Q_{\mathrm{wi}}\right)} \frac{\left[N_{\mathrm{i}} K_{\mathrm{wi}}+\left(1-N_{\mathrm{i}}\right) K_{\mathrm{wa}}\right] \tau_{\mathrm{w}}}{\frac{\tau_{\mathrm{w}} Q_{\mathrm{wa}} \gamma}{\rho_{\mathrm{w}} c_{\mathrm{pw}} H_{\mathrm{w}}} \frac{\rho_{\mathrm{a}}}{\rho_{\mathrm{w}}} \frac{\mathrm{d} q_{\mathrm{s}}\left(T_{\mathrm{w}}\right)}{\mathrm{d} T}-\frac{E}{\left(1-N_{\mathrm{i}}\right)}}
$$

which is the timescale for the change of evaporation rate due to the ocean warming/cooling induced by the ice advance/retreat, and:

$$
\tau_{\mathrm{S}} \equiv\left(\left\langle\dot{\varepsilon}_{\mathrm{h}}\right\rangle\right)^{-1}=\left[A\left[\frac{1}{4} \rho_{\mathrm{i}} g H_{1}\right]^{n}\right]^{-1}
$$

which is the ice-spreading timescale.

By using the values listed in Table $I$, these four timescales are estimated as:

$$
\begin{gathered}
\tau_{\mathrm{a}} \sim 11.6 \mathrm{~d}, \tau_{\mathrm{w}} \sim 66 \text { year, } \tau_{\mathrm{s}} \sim 3000 \text { year } \\
\left(\text { for } H_{1}=10 \mathrm{~m}\right), \tau_{\mathrm{e}} \sim 4660 \text { year }
\end{gathered}
$$

where we assume that $\left|Q_{\text {wa }}\right| \gg\left|Q_{\text {wi }}\right|$.

\section{TABLE I. MODEL PARAMETERS}

$$
\begin{array}{ll}
K_{\mathrm{ai}}=3 \times 10^{-2} \mathrm{~m} \mathrm{~s}^{-1} & K_{\text {wa }}=10^{-2} \mathrm{~m} \mathrm{~s}^{-1} \\
K_{\mathrm{wi}}=4 \times 10^{-5} \mathrm{~m} \mathrm{~s}^{-1} & \gamma=1.5 \times K_{\mathrm{wa}}(\mathrm{Gill}, 1982) \\
\text { (Josberger, 1987) } & H_{\mathrm{w}}=5 \mathrm{~km} \\
H_{\mathrm{a}}=8 \mathrm{~km} & Q_{\mathrm{wa}} /\left(\rho_{\mathrm{a}} c_{\mathrm{pa}} H_{\mathrm{a}}\right)=1 \mathrm{~K} \mathrm{~s}^{-1} \\
H_{\mathrm{i}}=2 \mathrm{~km} & n=3, A=3 \times 10^{-8} \mathrm{year}^{-1} \mathrm{kPa}^{-3} \\
N_{\mathrm{i}}=0.2 &
\end{array}
$$

Since the atmospheric and oceanic relaxation timescales $\tau_{\mathrm{a}}$ and $\tau_{\mathrm{w}}$ are so much shorter than the other two timescales $\tau_{\mathrm{s}}$ and $\tau_{\mathrm{e}}$, the atmospheric and oceanic temperature perturbations $T_{\mathrm{a}}^{\prime}$ and $T_{\mathrm{w}}^{\prime}$ almost "instantaneously" follow the ice advance/retreat processes, i.e.:

$$
T_{\mathrm{a}}^{\prime}=-A_{\mathrm{a}} \tau_{\mathrm{a}} N_{\mathrm{i}}^{\prime}, T_{\mathrm{w}}^{\prime}=A_{\mathrm{w}} \tau_{\mathrm{w}} N_{\mathrm{i}}^{\prime},
$$

where $A_{\mathrm{a}} \equiv\left(Q_{\mathrm{wa}}+Q_{\mathrm{ai}}\right) /\left(\rho_{\mathrm{a}} c_{\mathrm{pa}} H_{\mathrm{a}}\right), A_{\mathrm{w}} \equiv Q_{\mathrm{wa}} /\left(\rho_{\mathrm{w}} c_{\mathrm{pw}} H_{\mathrm{w}}\right)$. $\left(N_{1}^{\prime}>0\right)$ causes the cooling of the atmosphere $\left(T_{\mathrm{a}}^{\prime}<0\right)$ and the warming of the ocean $\left(T_{\mathrm{w}}^{\prime}>0\right)$. Substitution of Equation (17) into Equation (11) leads to the connection of lateral freezing rate $F^{\prime}$ to $N_{\mathrm{i}}^{\prime}$ :

$$
F^{\prime}=-H_{\mathrm{i}}\left(\alpha_{\mathrm{w}} A_{\mathrm{w}} \tau_{\mathrm{w}}-\alpha_{\mathrm{a}} A_{\mathrm{w}} \tau_{\mathrm{w}}\right) N_{\mathrm{i}}^{\prime}
$$

where $\alpha_{\mathrm{a}} \equiv \rho_{\mathrm{a}} c_{\mathrm{pa}} K_{\mathrm{a}} /\left(\rho_{\mathrm{i}} L_{\mathrm{i}} H_{\mathrm{i}}\right), \alpha_{\mathrm{w}} \equiv \rho_{\mathrm{w}} c_{\mathrm{pw}} K_{\mathrm{w}} /\left(\rho_{\mathrm{i}} L_{\mathrm{i}} H_{\mathrm{i}}\right)$.

\section{Stability parameters $\sigma$ and $v$}

Linearization of the basic Equations (2), (4), and (5) leads to:

$$
\frac{\partial N_{\mathrm{i}}^{\prime}}{\partial t}=N_{\mathrm{i}} n \tau_{\mathrm{s}}^{-1} \frac{\left(h_{\mathrm{i}}^{\prime}-h_{\mathrm{w}}^{\prime}\right)}{H_{1}}-\left(1-N_{\mathrm{i}}\right) \tau_{\mathrm{e}}^{-1} \sigma N_{\mathrm{i}}^{\prime}
$$

$$
\left[\frac{\partial}{\partial t}+\tau_{\mathrm{s}}^{-1}\right] h_{\mathrm{i}}^{\prime}=N_{\mathrm{i}} H_{\mathrm{w}} \tau_{\mathrm{e}}^{-1} N_{\mathrm{i}}^{\prime}
$$

$$
\frac{\partial h_{\mathrm{w}}^{\prime}}{\partial t}=-H_{\mathrm{w}} \tau_{\mathrm{e}}^{-1}\left[1-\left(1-N_{\mathrm{i}}\right) \mathrm{k} \sigma\right] N_{\mathrm{i}}^{\prime}
$$

where $\boldsymbol{k} \equiv \rho_{\mathrm{i}} H_{\mathrm{i}} /\left(\rho_{\mathrm{w}} H_{\mathrm{w}}\right)$, and $\sigma$ is a non-dimensional parameter defined by:

$$
\sigma \equiv \tau_{\mathrm{e}}\left(\alpha_{\mathrm{w}} A_{\mathrm{w}} \tau_{\mathrm{w}}-\alpha_{\mathrm{a}} A_{\mathrm{a}} \tau_{\mathrm{a}}\right) .
$$

For $\sigma>0$, the ice has a "restoring force" induced by the ice advance/retreat. The mechanical feedback of the air and ocean into the ice can be easily noticed from the feedback of $h_{\mathrm{i}}^{\prime}$ and $h_{\mathrm{w}}^{\prime}$ change due to $N_{\mathrm{i}}^{\prime}$, into the ice advance/retreat through the first term in the righthand side of Equation (19). This feedback largely depends on the parameter $v \equiv H_{\mathrm{w}} / H_{1}$. The larger the value of $v$, the stronger this feedback mechanism will be. Figure 3 shows the relationships among the model variables.

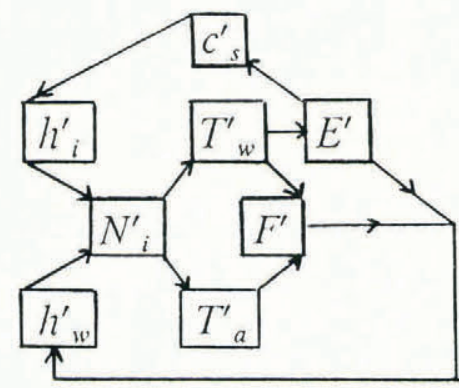

Fig. 3. Relationships among the model variables.

The general solutions of Equations (19), (20) and (21) have the following forms:

$$
N_{\mathrm{i}}^{\prime}(t)=\Sigma b_{j} \mathrm{e}^{\omega_{j} t}, h_{\mathrm{i}}^{\prime}(t)=\Sigma c_{j} \mathrm{e}^{\omega_{j} t}, h_{\mathrm{w}}^{\prime}(t)=\Sigma d_{j} \mathrm{e}^{\omega_{j} t}
$$

where $b_{j}, c_{j}$, and $d_{j}(j=1,2,3)$ are the integral constants, and $\omega_{1}, \omega_{2}$, and $\omega_{3}$ are the eigenvalues which are the roots of the third-order algebraic equation:

$$
\omega^{3}+a_{1} \omega^{2}+a_{2} \omega+a_{3}=0 .
$$

\section{RESULTS}

We compute all roots of Equation (24) for different values of the parameters $\sigma$ and $v$, and obtain three roots at each pair of the parameters $(\sigma, v)$. One root among the

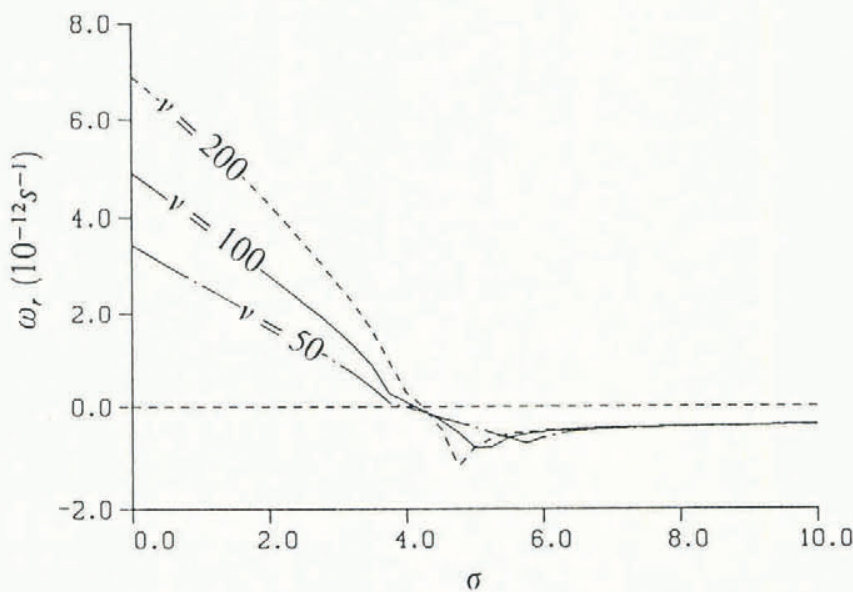

Fig. 4. Dependence of growth rate $\omega_{r}$ on stability parameters $\sigma$ and $v$. 
three has a negative real part throughout the whole parameter space, representing the damping modes, in which we are not interested here. The other two roots, $\omega_{1}$ and $\omega_{2}$, have positive real parts somewhere in the parameter space, representing the existence of growing modes in certain parameter ranges. Figure 4 shows the dependence of growth rate $\left(10^{-12} \mathrm{~s}^{-1}\right)$ on $\sigma$ for three different values of $v$. The horizontal axis $\sigma$ changes from 0 to 10 , representing the increase of thermodynamic stability. Oscillation takes place only in certain range of $\sigma$ (Table II), i.e. for $\sigma_{\mathrm{H}} \geqslant \sigma \geqslant \sigma_{\mathrm{L}}$, $\omega_{\mathrm{i}} \neq 0$. Out of this range, i.e. for $\sigma<\sigma_{\mathrm{L}}$, or $\sigma>\sigma_{\mathrm{H}}$, $\omega_{i}=0$, which represents non-oscillatory modes. Figure 5 shows the dependence of the period $\left(2 \pi / \omega_{i}\right)$ on $\sigma$ for three different values of $v$.

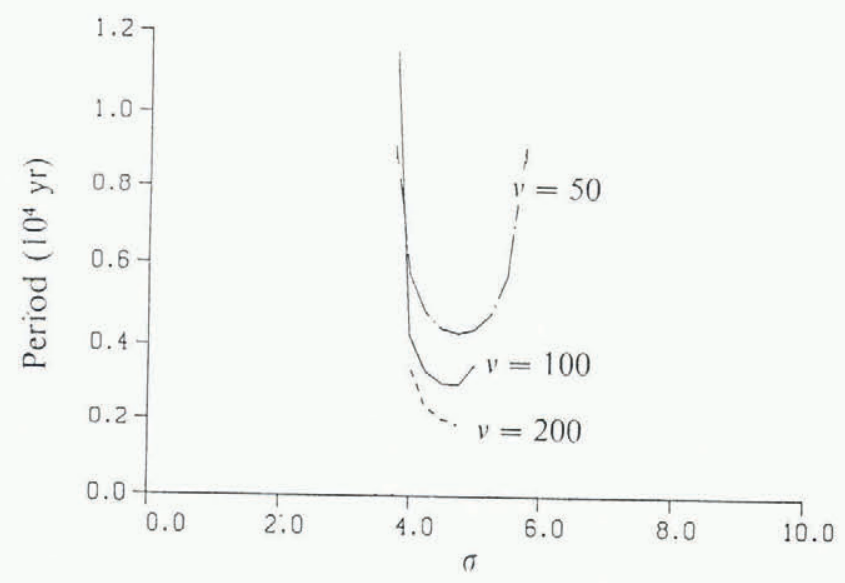

Fig. 5. Dependence of period of oscillatory modes, $2 \pi /\left|\omega_{i}\right|$, on stability parameters $\sigma$ and $v$.

TABLE II. THE OSCILLATION INTERVALS

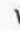

$\begin{array}{rrr}50 & 3.75 & 5.75 \\ 100 & 3.75 & 5.00 \\ 200 & 4.00 & 4.75\end{array}$

The results are listed below:

(1) The two parameters $\sigma$ and $v$ play different roles in the coupled system. The negative feedback measured by $\sigma$ stabilizes the system; however, the positive feedback measured by $v$ destabilizes the system. Because of the existence of positive feedback mechanisms, the coupled system is unstable unless the parameter $\sigma$ exceeds some critical value $\sigma_{\mathrm{c}}$. Figure 4 indicates that $\sigma_{\mathrm{c}}=4.25$.

(2) Four different types of modes are generated due to the relative strength of positive to negative mechanism:

$\sigma<\sigma_{L}$, non-oscillatory growing,

$\sigma_{L} \leqslant \sigma \leqslant \sigma_{C}$, oscillatory growing,

$\sigma_{\mathrm{C}} \leqslant \sigma \leqslant \sigma_{\mathrm{H}}$, oscillatory damping,

$\sigma>\sigma_{\mathrm{H}}$, non-oscillatory damping.
(3) The parameter $v$ serves as an instability parameter. In the growing regime (Fig. 4), the larger the value of $v$, the larger the growth rate will be. The mean growth rate of the growing modes varies from $2-6 \times 10^{-12} \mathrm{~s}^{-1}$. The doubling time during which the perturbation doubles its strength is:

$$
T_{\mathrm{d}}=\frac{\ln 2}{\omega_{\mathrm{r}}} \sim 3660-11000 \text { year. }
$$

(4) The parameter $v$ also largely impacts on the periodicity of the coupled system. First, $v$ affects the critical values of $\sigma_{L}$ and $\sigma_{H}$. The larger the value of $v$, the smaller the range of oscillatory mode will be. The mean period varies from 2000-3000 years (for $v=200$ ) to $4000-12000$ years (for $v=100$ ).

\section{CONCLUSION}

This conceptual air-ice-ocean coupled model shows a possible positive/negative feed-back mechanism, induced by the hydrological cycle, among the atmosphere, ice, and ocean. The theory predicts the generation of oscillations in ice coverage, ice thickness, air and ocean temperatures, and sea-level height, on the time scale of $10^{3}-10^{4}$ years.

\section{ACKNOWLEDGEMENTS}

This research was sponsored by the U.S. National Science Foundation, the U.S. Office of Naval Research, and the Naval Postgraduate School.

\section{REFERENCES}

Chu, P.C. 1989. Relationship between thermally forced surface wind and sea surface temperature gradient. Pure Appl. Geophys., 130, 31-45.

Gill, A.G. 1982. Atmosphere-ocean dynamics. New York, Academic Press.

Josberger, E.G. 1987. Bottom ablation and heat transfer coefficients from the 1983 Marginal Ice Zone Experiments. J. Geophys. Res., 92(7), 7012-7016.

Källén, E., C. Crafoord, and M. Ghil. 1979. Free oscillations in a climate model with ice-sheet dynamics. $J$. Atmos. Sci., 36(12), 2292-2303.

Killworth, P.D. 1979. On "chimney" formations in the ocean. J. Phys. Oceanogr., 9, 531-554.

Oerlemans, J. and C.J. van der Veen, jr. 1984. Ice sheets and climate. Dordrecht, etc., D. Reidel Publishing Company.

Shumskiy, P.A. 1965. A study of ice in the Arctic Ocean. Dokl. Akad. Nauk SSSR, 162, 320-322.

Weertman, J. 1957. Deformation of floating ice shelves. $J$. Glaciol., 3(21), 38-42.

Weertman, J. 1973. Creep of ice. In Whalley, E., S.J. Jones, and L.W. Gold, eds. Physics and Chemistry of Ice. Papers presented at the Symposium ... 1972. Ottawa, Royal Society of Canada, 320-337. 